\title{
Das perguntas wittgensteinianas à pedagogia das competências: ou desmontando a caixa-preta de Perrenoud'
}

\author{
Rafael Ferreira de Souza Mendes Pereira"
}

\section{Resumo}

Este artigo faz parte de uma pesquisa de mestrado que se propõe a analisar conceitos educacionais e curriculares por meio da filosofia da linguagem elaborada por Ludwig Wittgenstein. Dessa perspectiva, examinamos alguns pressupostos teóricos da chamada pedagogia das competências e interrogamos se esse modelo pedagógico, em nome de pretensa renovação do ensino, não encorajaria a reificação de conceitos mentais concernentes ao processo de aprendizagem. Com este fim, abordamos a reformulação que essa pedagogia oferece a respeito de conceitos como aprender, saber, compreender, destacando as ambiguidades daí decorrentes. Argumenta-se que é possível obter uma leitura mais rigorosa das suas propostas de modernização pedagógica se investigarmos o uso dado a esses conceitos nos jogos de linguagem em que eles são mobilizados. Wittgenstein, na segunda fase de sua produção intelectual, mostrou como a negligência linguística à dinâmica que dá significado aos conceitos e metáforas referentes à nossa vida mental fez com que diversas filosofias assumissem um perfil metafísico. Este artigo não apenas examina como um fenômeno análogo pode ocorrer no campo pedagógico, como também defende que as ferramentas analíticas construídas por Wittgenstein podem ser usadas contra os diferentes dogmatismos pedagógicos. Desse modo, o artigo aponta vias alternativas de problematização acerca do significado das reformas dos sistemas escolares que têm buscado fundamentos naquela pedagogia.

I- Agradeço aos membros do grupo de pesquisa de Filosofia, Educação, Linguagem e Pragmática (FELP-FEUSP), coordenado pela Profa. Cristiane Gottschalk, cujas generosas críticas enriqueceram este artigo durante a fase de sua elaboração.

II- Universidade de São Paulo, São Paulo, SP, Brasil.

Contato: rfspereira@yahoo.com.br

\section{Palavras-chave}

Pedagogia - Filosofia - Análise conceitual - Dogmatismo. 


\title{
Wittgensteinian questions to the pedagogy of competences'
}

\author{
Rafael Ferreira de Souza Mendes Pereira"
}

\begin{abstract}
This article is part of a Master's research that aims at analyzing educational and curricular concepts by means of the philosophy of language developed by Ludwig Wittgenstein. From this perspective, I examine some theoretical assumptions of the so-called pedagogy of competences and question whether this pedagogical model, in the name of the alleged renewal of teaching, encourages the reification of the mental concepts concerning learning processes. To this end, I examine the recast that this pedagogy offers of concepts such as learning, knowledge and understanding, highlighting the ambiguities that arise from them. It is argued that it is possible to obtain a more precise reading of its proposals of educational modernization if we investigate the use of those concepts in the language games in which they are deployed. In the second phase of Wittgenstein's intellectual production, he showed how linguistic neglect of the dynamics that gives meaning to the concepts and metaphors related to our mental life has made many philosophies assume a metaphysical profile. This article not only examines how a similar phenomenon may occur in the educational field but also argues that the analytical tools built by Wittgenstein can be used against different pedagogical dogmatisms. Thus, the article outlines alternative ways of questioning the meaning of the reforms of school systems that have sought grounds in the pedagogy of competences.
\end{abstract}

\section{Keywords}

Pedagogy - Philosophy - Conceptual analysis - Dogmatism.

I- I wish to thank the members of the research group Filosofia, Educação, Linguagem e Pragmática (FELP - Philosophy, Education, Language and Pragmatics), coordinated by Professor Cristiane Gottschalk. Her generous criticism has enriched this article.

II- Universidade de São Paulo, São Paulo, SP, Brasil.

Contact: rfspereira@yahoo.com.br 


\section{Pedagogia das competências:}

currículo e epistemologia

Nos dias que correm, da educação infantil ao ensino superior, no ensino público e privado, somos frequentemente interpelados, quando não pressionados, a planejar e justificar nossa ação educacional sob a referência do desenvolvimento de habilidades e competências. É cada vez mais raro encontrar um documento educacional em que $o$ vocabulário das competências não figure. Nesse contexto, essa pedagogia se expõe (e nos expõe) a um grande perigo, que não se resume à possibilidade de assumir uma tendência dogmática sob a égide de suposta modernização escolar, mas se estende à perda da clareza de suas asserções inquestionáveis, pois "as proposições difíceis de rejeitar são também as mais fáceis de obscurecer" (PERELMAN, 1996, p. 150).

Uma parte desse obscurecimento decorre seguramente dos abusos a que o modismo e a vulgarização submetem essa pedagogia, mas isso não é tudo. 0 problema possui raizes teóricas mais profundas. Para sondá-las, seria de grande interesse a realização de uma genealogia das matrizes desse discurso, que nos faria recuar pelo menos até os anos setenta, trabalho em parte realizado por Ropé e Tanguy (1997). Outro caminho possivel (e é este que escolhemos) é a análise direta dos argumentos e pressupostos de uma das vozes autorizadas dessa pedagogia. Com esse intento, são debatidas nas próximas linhas as ideias do sociólogo suíço Philippe Perrenoud. Veremos que a ambiguidade que se poderia atribuir criticamente à vulgarização do discurso da pedagogia das competências está também presente nos argumentos de um dos seus principais teóricos, principalmente quando este flerta com certo essencialismo cognitivo.

Perrenoud propõe a construção de uma nova identidade docente por meio da superação de certas tradições profissionais, dentre elas a sobrevalorização das aulas em estilo magistral, cujo brilho esconderia a ilusória pretensão de organizar a sequência do saber na cabeça do aluno (PERRENOUD, 1999). 0 teórico propõe que se abandone este sonho de controle sobre a cognição do aluno em nome de uma concepção mais prática de saber e mais ativa de aluno. Embora a crítica do autor não seja desprovida de razão, ele parece reeditar sub-repticiamente aquele sonho num outro contexto, já que sua proposta pedagógica seria endossada pelo avanço vindouro das ciências cognitivas, aptas a abrir a "caixa-preta da cognição das operações mentais" (PERRENOUD, 1999, p. 20). Tal expectativa, quando extrapola o campo da investigação científica para nortear políticas educacionais, pode ter efeitos deletérios, principalmente porque as regras do jogo nesses dois campos não são idênticas. Mas só chegaremos a esse ponto no fim do artigo. Antes, esclareceremos algumas questões preliminares.

A pedagogia das competências defende uma nova concepção de cultura e de saber. Segundo Perrenoud, o privilégio dado à transmissão do patrimônio cultural como princípio organizador do ensino escolar tende a valorizar o enciclopedismo em detrimento dos aspectos pragmáticos do conhecimento. 0 autor exemplifica os males daí decorrentes por meio da seguinte situação (PERRENOUD, 1999, p. 21-22). Muitos alunos que, por anos a fio, estudaram listas de conjugação e regras gramaticais da língua inglesa na escola, quando são subitamente interpelados, durante um passeio, por um turista inglês em busca de informações, mal balbuciam um Sorry, I don't understand. Isso prova que eles não aprenderam? Esqueceram tudo? Nada disso. Segundo Perrenoud, o aluno em questão possui conhecimentos, mas não construiu competências, resultado que assinalaria a falência do ensino que apresenta o conhecimento como um fim em si mesmo, em vez de tratá-lo como um instrumento a ser mobilizado para enfrentar situações problemáticas. A aquisição de conhecimentos não seria o mesmo que o 
desenvolvimento de competências. Essa parece uma asserção inofensiva, mas merece toda a nossa atenção.

Em entrevista à Revue Vie Pédagogique, questionado por Luce Brossard acerca da dificuldade de se definir as competências em domínio escolar, Perrenoud lhe replicou da seguinte maneira:

A competência é uma capacidade de agir eficazmente em face de uma família de situações, que se chega a dominar porque se dispõe simultaneamente de conhecimentos necessários e da capacidade de mobilizá-los ciosa e oportunamente para identificar e resolver verdadeiros problemas ${ }^{1}$. (PERRENOUD, 1999a).

Portanto, as competências são irredutíveis a conhecimentos, embora se apoiem sobre eles. Em outras palavras, os conhecimentos disciplinares não se integram espontaneamente em competências. Razão pela qual os currículos deveriam ser reorganizados em função de situações-problema aptas a fomentar a construção de competências desde a escola. Eis a nova finalidade da formação escolar: não mais ensinar, mas fazer aprender (PERRENOUD, 1999).

Essa reformulação curricular proposta pela pedagogia das competências decorre de uma epistemologia de perfil pragmático e anti-intelectualista que, segundo Perrenoud, é uma das fontes da grande relutância enfrentada pelas suas propostas (PERRENOUD, 1999). Sem dúvida, podemos dizer que, no campo educacional, as representações intelectualistas do conhecimento, se não forem dominantes, são ao menos extremamente influentes. Grosso modo, podemos afırmar que, nessas representações, o fundamento que dá legitimidade e objetividade ao conhecimento do individuo é uma subjetividade universal, cuja interioridade se opõe à

1- A tradução é do autor do artigo. E a íntegra da entrevista está disponível no site da Universidade de Genebra, onde se podem encontrar diversas entrevistas e artigos de Perrenoud inéditos no Brasil: <http://www.unige. ch/fapse/SSE/teachers/perrenoud/php_main/php_1999/1999_14.html>. Acesso 10 set. 2014> exterioridade do mundo-objeto e se relaciona com este por meio de uma relação calculadora, aplicacionista e instrumental. As epistemologias de corte intelectualista hierarquizam a relação entre operações mentais e ação prática, entre teoria e comportamento, de modo que as primeiras sempre precedem e legislam sobre as segundas. Dito isso, não é difícil imaginar as delicadas relações entre epistemologia e pedagogia que estão em jogo nessa tradição. Com efeito, um modelo de ensino fundamentado numa epistemologia intelectualista provavelmente encontrará sérias dificuldades práticas e metodológicas. Senão, vejamos.

A maioria das atividades que realizamos com êxito e confiança, tal como usar a língua materna, por exemplo, não nos foram ensinadas por meio de lições teóricas, tampouco necessitamos consultar regras para executá-las. E, embora outras atividades, tais como elaborar uma hipótese, mediar conflitos ou declamar um poema, possam ser mais facilmente ensinadas por meio da formalização de suas regras, o êxito nessas atividades não estará de nenhum modo assegurado por causa disso.

Tais formalizações exigem uma extrema simplificação dos problemas, procedimento apropriado para a criação de situações ideais em que a boa fórmula se aplica confortavelmente. Todavia, simplifıcações didáticas como essas correm o risco de formar alunos qualificados para problemas abstratos que, não obstante, mostrem-se inaptos frente a problemas análogos transpostos para situações concretas complexas. Por essa razão, Perrenoud (1999, p. 60) advoga, em detrimento do ensino por meio de lista de exercícios abstratos e repetitivos, a introdução de situações-problema no currículo escolar.

Assim caracterizados os limites pedagógicos das epistemologias intelectualistas, cabe-nos discutir quais implicações podem deles ser extraídas. De um ponto de vista wittgensteiniano, a alternativa representada pela pedagogia das competências traz, em vários aspectos, mais impasses que soluções. 


\section{O aprendizado entre a repetição e a resolução de problemas}

É o cenário da sociedade em transição, composto por transformações tecnológicas e desregulamentação econômica, que Perrenoud evoca para defender a formação escolar de sujeitos capazes de gerir a incerteza, tais como um cientista (PERRENOUD, 1999, p. 63). Para o pensador suíço, a competência do cientista manifesta-se especialmente não quando ele obedece às regras preestabelecidas pelo método, mas quando as reformula ou mesmo as abandona para poder solucionar problemas não rotineiros de pesquisa. 0 novo currículo, inspirado nesse modelo, deve ser estruturado por situações-problema cuja resolução exija do aluno mais do que a capacidade de perceber analogias evidentes entre um exercício e outro (PERRENOUD, 1999). Tal transformação curricular deve ser radical, sem concessões:

Se tais atividades [práticas em resolução de problemas] se multiplicarem, contribuirão para implementar verdadeiros esquemas de mobilização de conhecimentos. Se forem mais ocasionais, permitirão ver um modo possível de mobilização, sem formar realmente competências, talvez induzindo uma outra relação com o saber, ao incitar alunos a adotarem uma postura ativa, a considerarem os conhecimentos como chaves para fechaduras desconhecidas, cuja descoberta pode ser esperada um dia ou outro. (PERRENOUD, 1999, p. 23).

Seja como expediente didático ocasional ou como disciplina específica do currículo, a admissão parcial do ensino por meio da resolução de problemas é considerada insuficiente para a construção de competências. Entre a escola da repetição de exercícios e a escola da resolução de problemas, o autor estabelece, portanto, uma oposição enfática. Devemos compreendê-la como um recurso estilístico apropriado ao gênero polêmico em questão? Ou será essa oposição de fato inconciliável, efeito da distinção entre conhecimento e competência? ${ }^{2}$

A resposta afirmativa a esta última pergunta levar-nos-ia a uma interpretação forte e literal das palavras de Perrenoud. É nesse sentido que aponta Michel Tozzi, filósofo que aplicou o modelo do desenvolvimento das competências ao campo do ensino da filosofia: "É preciso distinguir uma competência (que implica um saber vivo) de um saber descontextualizado, separado das tarefas e situações” (TOZZI, 2012, p. 25).

Essa primeira interpretação é atraente, mas, ao vincular o saber/conhecimento sem competência ao saber descontextualizado, leva-nos ao encontro de um paradoxo. Afınal, quando alguém faz afirmações fora de contexto, não dizemos que ele possui conhecimentos desvinculados de competências, dizemos que suas afırmações são impertinentes, obscuras ou sem sentido. Do contrário, teríamos de admitir uma expressão como "sicrano tem muito conhecimento na área de física, mas não sabe como nem onde empregá-lo", o que seria um uso muito inusitado da palavra conhecimento. Assim como não dizemos que aprendeu a jogar xadrez quem memorizou o nome das suas peças, não diremos que sabe o significado de um conceito alguém que não sabe o papel que ele desempenha na linguagem (WITTGENSTEIN³ ${ }^{3}$ 1999, \# 30).

A generalização das situações-problema no currículo agora pode ser compreendida por outro ângulo. A pedagogia das competências, e muitas outras pedagogias renovadas, com razão, denunciaram os efeitos nocivos da memorização de informações descontextualizadas, da transmissão enciclopédica de conceitos etc., em nome de um aprendizado mais reflexivo e de um aluno mais autônomo. Todavia, cabe-nos perguntar se a radicalidade da reforma proposta não encontra um obstáculo justamente no fato de a resolução por problemas ter por

2- Estas alternativas não são excludentes. Com efeito, retomamos a linha interpretativa estilística ao fim do artigo.

3- Como Wittgenstein numerava seus parágrafos, convencionou-se citar sua obra por referência a eles. Por isso, não remetemos às páginas da edição. 
pré-requisitos, em grande número de casos, se não em todos, a aceitação de instruções e a realização prévia de exercícios minimamente repetitivos. Tais pré-requisitos dizem respeito ao domínio das regras do jogo que se pretende ensinar ${ }^{4}$. Embora seja possível entrar em alguns jogos sem saber todas as regras e, não obstante, ir aprendendo-as ao longo da partida, isso nem sempre é possível e, quando o é, nem sempre é o jeito mais fácil ou fecundo. Por mais repetitivo que seja o aprendizado da tabuada, é difícil entender por que privaríamos os alunos dela. Pode ser fácil e divertido aprender a dançar sendo jogado no meio da roda, mas deduzir as regras de conjugação verbal de uma língua estrangeira a partir da leitura de textos sem o auxílio das tabelas de conjugação é certamente extenuante.

Se, por um lado, a execução de exercícios repetitivos pode levar o aluno a aplicar regras sem pensar, por outro, a resolução de problemas complexos e imprevistos que exigem reflexão e discernimento também pressupõem certo automatismo em nossas condutas. Pensemos, por exemplo, na aplicação das tabelas de conjugação verbal já internalizadas pelo tradutor de poesias. Aqui, o discernimento supõe e se alia ao automatismo. Por isso, não convém forjar um abismo entre o currículo das situações-problema e o currículo dos exercícios repetitivos, de tal modo que as relações de dependência mútua e as gradações entre automatismo e discernimento, entre tradição e criticismo, entre repetição e inovação, entre regularidade e improvisação terminem simplificadas e negligenciadas. Ao contrário, é preciso notar que a condição necessária (ainda que não suficiente) da relação ativa com o saber é, em um primeiro momento, certa passividade, e que, além disso, a passagem entre a autonomia e a heteronomia do aprendiz na aprendizagem de um conceito não pode ser demarcada pela exatidão de uma fronteira. Isso se observa desde o aprendizado de conceitos corriqueiros até processos de aquisição de conceitos mais complexos.

4 - 0 próximo item explicará como deve ser entendido o conceito de jogo.
Wittgenstein (1999), em uma passagem das Investigações filosóficas, no interior de sua polêmica com a filosofia mentalista ${ }^{5}$, pede que imaginemos uma pessoa que não conheça o conceito de mesmo. Como lhe ensinaríamos o conceito? Por meio de exemplos e pela prática, sem dúvida. Daríamos exemplos de coisas com a mesma forma, objetos com a mesma cor, mostraríamos um padrão ornamental com que enfeitamos a casa e pediríamos que ela nos ajudasse etc. Quando ela acertasse, a encorajaríamos, quando se equivocasse, a reprovaríamos, até que, a partir de certo momento que não podemos prever, ela ultrapassasse os exemplos e, por fim, prosseguisse por si só, aplicando o conceito em contextos novos. Nesse processo, o limite entre a imitação do mestre e a utilização autônoma de um conceito existe, mas certamente não pode ser estabelecida com exatidão.

0 conjunto de ações que conduziu o aprendizado no exemplo acima - ordenar, reprovar, encorajar, enfim, treinar - pode parecer-se em tudo avesso à formação dos alunos reflexivos, capazes de enfrentar situações problemáticas complexas, mas não se olharmos mais de perto. Tomemos o caso do aprendizado científico, lembrando que, para Perrenoud, o cientista é o exemplo paradigmático de mobilização de competências.

Tomas Kuhn, levando a sério a lição de Wittgenstein, mostrou que os pesquisadores identificam como cientificamente relevantes os mesmos problemas somente após passarem pela mesma educação profissional numa comunidade científica que, na medida em que os inicia a um paradigma normal, ensina-os a ver aspectos da natureza como problemáticos e, claro, certas soluções como exemplares ${ }^{6}$ (KUHN, 1998). 0 que torna possível a compreensão e

5- Cf. Wittgenstein, 1999, \# 208. 0 mentalismo, grosso modo, designa as teorias que postulam a existência de entidades mentais extralinguísticas que guiariam a aplicação de nossos conceitos. Ali está em jogo todo o debate sobre o seguir regras que eu não posso aprofundar no momento.

6- As reflexões linguísticas de Wittgenstein foram centrais para a elaboração do conceito kuhniano de paradigma. A este respeito, ver Kuhn (1998, p. 68-ss). 
aprendizado dessas explicações? A esse respeito, Wittgenstein é enfático: “Toda a explicação tem seu fundamento no treino (Os educadores deviam lembrar-se disto.)" (WITTGENSTEIN, 1981, \# 419). Os problemas são vistos como tais por aqueles que estão treinados em determinadas técnicas de problematização, pois o que vale para a linguagem em geral vale para a linguagem cientifica, a saber, "compreender uma linguagem significa dominar uma técnica" (WITTGENSTEIN, 1999, \# 199). Desse modo, embora a ideia possa deixar muitos educadores de cabelo em pé, é preciso dizer que uma pedagogia que promova o treinamento ${ }^{7}$ e, ao mesmo tempo, almeje formar um sujeito autônomo - seja ele o aluno crítico, reflexivo ou competente - não comete nenhuma contradição.

Se quisermos destacar na atividade científica sua dimensão criadora - ou a capacidade de "gerir a incerteza", como prefere Perrenoud, devemos lembrar que a iniciação aos paradigmas consolidados na comunidade científica não lhe fornece só métodos e normas, mas também modelos de criatividade, de onde o sujeito colhe parâmetros para diferenciar uma inovação de um mero disparate. A racionalidade científica, como o espírito crítico de modo geral, são frutos de certa tradição e, por isso, abolir a dimensão instrutiva do ensino, reduzindo-o à resolução de situações-problemas, em nome da autonomia e da reflexividade dos aprendizes, parece-nos um contrassenso. Afinal, não poderia participar das tradições críticas quem não tivesse sido nelas iniciado - sem tal iniciação, formaríamos estudantes despreparados para fazer frente aos principais problemas construídos por essa tradição $0^{8}$. Se, inspirados em Wittgenstein, entendermos essa tradição como um conjunto de jogos de linguagem, podemos rever a imagem que fazemos do aluno crítico.

7- A melhor tradução do termo alemão Arbrichtung, usado por Wittgenstein, não é treinamento, pois a palavra se refere especialmente ao treinamento de animais, ou seja, o termo seria melhor traduzido por adestramento.

8- Esta conclusão é também apoiada pelas análises de Passmore (1969)

\section{O ensino e os jogos de linguagem}

Wittgenstein, na segunda fase de sua filosofia, considera o significado de uma palavra inseparável do seu uso no interior de certo jogo de linguagem (WITTGENSTEIN, 1989, \# 43). Esta expressão analógica ressalta que as diferentes linguagens, assim como os jogos, são práticas reguladas por padrões públicos que definem quais lances (ou signos) são admitidos. Ao descrever as regras do(s) jogo(s) ou, como prefere Wittgenstein (1999, \# 90 e 124), a gramática dos jogos, o filósofo não determina o que é verdadeiro, mas mostra o que pode ser dito com sentido, seja verdadeiro ou falso. Wittgenstein diz: "Chamarei de 'Jogos de linguagem' o conjunto da linguagem e das atividades com as quais está interligada" (WITTGENSTEIN, 1999, \# 7).

Desse conjunto, o filósofo apresenta-nos uma lista não exaustiva que inclui atividades como relatar um acontecimento ou um sonho, inventar uma história, contar piadas, fazer um plano e executá-lo, resolver enigmas, levantar hipóteses e verificá-las etc. ${ }^{9}$ Se nos é apresentada tal lista em lugar de uma definição, é porque:

Para Wittgenstein não se compreende a linguagem em si, se compreende um jogo de linguagem determinado, situando-se a si mesmo no tal jogo, isto é, numa atitude particular, em um modelo de atividade, em uma forma de vida. (HADOT, 2005, p. 73).

Como o critério que indica a compreensão do papel de um conceito em certo jogo é a atitude que o sujeito mostra em determinado contexto, o aprendizado não pode se resumir a fenômenos intelectuais separados de uma práxis ${ }^{10}$.

Wittgenstein estende esse modelo dos jogos a atividades como a filosofia e a ciência.

9- Esta lista é uma pequena variação daquela apresentada pelo próprio Wittgenstein no \# 23 das Investigações Filosóficas.

10- Como esclarece Moreno: "as diversas práticas ligadas à linguagem são 0 meio através do qual são estabelecidas as ligações entre signos e objetos e, além disso, são instrumentos linguísticos. É nesse sentido que tais práticas fazem parte da gramática dos usos" (MORENO, 1995, p. 25). 
São linguagens que não possuem nenhuma natureza extraordinária que poderia lhes conferir privilégios sobre a linguagem cotidiana. São simplesmente jogos cujas regras estão fundamentadas em formas de vida, modos institucionalizados de agir e julgar. Radicalizada essa perspectiva, já não se busca fora dos reinos da linguagem - o ser, as ideias ou a experiência um sítio onde a significação poderia habitar; livramo-nos do anseio que nos levaria a cortar o galho da linguagem onde estamos sentados (WITTGENSTEIN, 1999, \# 57). As ciências naturais já não são a voz própria da natureza, pois "O único correlato da linguagem a uma necessidade natural é uma regra arbitrária" (WITTGENSTEIN, 1999, \# 372). A própria interioridade não será poupada. Wittgenstein, a esse respeito, interroga:

0 que se passa quando alguém fala consigo mesmo? 0 que se passa aí? - Como devo esclarecer isso? Ora, apenas do modo como você pode ensinar a alguém a significação da expressão "falar consigo mesmo". E, quando criança, aprendemos essa significação. (WITTGENSTEIN, 1999, \# 362).

Em outras palavras, o que sabemos e podemos ensinar a respeito da interioridade e seus atos (como a reflexão, por exemplo) resumem-se a critérios instituídos culturalmente por meio do uso de palavras em circunstâncias particulares. Enfım, não ouvimos a voz da natureza ou da nossa interioridade senão por meio de usos convencionados por nossa forma de vida em certo jogo de linguagem.

A abordagem do fenômeno educativo por meio do conceito de jogos de linguagem convida-nos a enfatizar as regras do jogo. Contudo, não implica nenhuma pedagogia do conformismo, ainda que nos leve a relativizar o signifıcado da problematização realizada pelo aluno. Nesse sentido, a passividade do aluno não é mais a única conclusão que podemos extrair da sua ausência de questionamento que, em certos contextos, poderá ser interpretada como sinal de domínio de um jogo e suas regras. Afinal, como afirma Wittgenstein em $D a$ certeza: "Quem põe certas dúvidas joga mal ou não joga ainda” (WITTGENSTEIN, 1990, \# 446).

Há perguntas, dúvidas ou críticas que, quando manifestas pelo aluno, possibilitam ao professor inferir a dificuldade em que ele se encontra diante do desafio de aprender um conceito ou construir um problema: “o aluno não aprendeu a fazer perguntas. Não aprendeu o jogo que queremos ensinar-lhe" (WITTGENSTEIN, 1990, \#315). Ou ainda: "Esta dúvida não é uma das dúvidas do nosso jogo" (WITTGENSTEIN, 1990, \#317). Quando dizemos que a escola precisa mostrar as regras do jogo e explicitar modelos de conduta ou métodos (algumas jogadas) para os alunos, ressaltamos que o sentido e o valor dos problemas construídos no interior desses jogos são frutos de convenções e que, portanto, não se revelarão espontaneamente à maioria dos alunos ${ }^{11}$.

Os modelos oferecidos para os alunos na escola lá estão para serem seguidos, mas também para serem reconhecidos em seus limites, quando podem ser razoavelmente transpostos e eventualmente recusados, o que também faz parte do seu aprendizado. Isso pode ser feito de muitas formas. Por exemplo, mostrar as limitações e as razões que levaram homens e mulheres a questionarem uma defınição estreita de direitos humanos (restrita à esfera dos direitos civis), ampliando-a para o campo dos direitos sociais. $\mathrm{Ou}$, ainda, mostrar exemplos em que o conceito de solidariedade é recusado por não se confundir com gregarismo ou espírito de rebanho. 0 domínio dessa técnica de transposição do uso de regras (subsumir um caso a um conceito não usual ou criar um conceito) pode ser facilitada em grande medida se mostramos ao aluno que o agrupamento de dois ou mais casos sob um conceito é uma convenção, ou melhor,

11- A adesão do aluno a um modelo é uma questão complexa e seu desenvolvimento numa perspectiva wittgensteiniana envolveria um debate de conceitos como persuasão e crença, normalmente considerados secundários na tradição racionalista. A este respeito, ver Wittgenstein (1990, \#\# 160-ss e \# 612). 
uma instituição e, portanto, uma invenção conceitual. Promover essa atitude no âmbito da escola pode ser um modo de preservar e legar a racionalidade particular que representamos enquanto professores, ao mesmo tempo em que mostramos a maneira como ela foi construída, em lugar de outras possíveis.

Por trás desse esforço pedagógico, não se encontra nenhum arroubo racionalista que pretenderia legar aos alunos a regra que preside a invenção das regras. 0 importante aqui é evidenciar que os conceitos ou soluções que vingam respondem a critérios públicos (ou publicáveis) de uso, condição necessária para que eles não se percam em uma insondável linguagem privada. A esse respeito, o comentário de Moreno a respeito da invenção em estética é esclarecedor:

[...] objetos de categorias diferentes, como sons e cores, podem ser comparados uma vez que forem propostos padrões para sua comparação: os conceitos de "som colorido" ou de "cor sonora" correspondem a certas operações de comparação entre tais objetos, comparações que, para serem públicas, e não meramente privadas, devem passar pelo teste de perguntas e respostas, das indicações sobre procedimentos de comparação. (MORENO, 2005, p. 314).

Por fim, vale a pena esclarecer que afirmar que o significado do conceito $\mathrm{X}$ é o próprio uso regular do conceito X não congela a sua significação, uma vez que uso se refere a um consenso de ação que, no mais, antes abre do que fecha possibilidades, antes indica uma direção do que estabelece uma regulação exaustiva. Não é uma essência comum que unifica objetos diversos sob um mesmo conceito, mas um conjunto de aspectos (destacados pelo uso) que mantém entre si relações analógicas. Por essa razão, dirá Wittgenstein que as diferentes aplicações de um mesmo conceito se relacionam por semelhanças de família, vínculos cuja vagueza não é um defeito, mas garantia tanto da unidade quanto da mobilidade do conceito $^{12}$. Sem esta vagueza, o aprendiz não conseguiria compreender os exemplos que se lhe fornecem de um conceito ao ponto de ultrapassá-los e aplicá-lo a casos novos, isto é, não exemplificados. Por outro lado, é essa vagueza que torna possível o surgimento da dúvida e da polêmica nas aplicações de um conceito, bem como a inovação em suas aplicações. Ou seja, essa vagueza permite tanto a manutenção da aplicação de uma regra sobre objetos mais ou menos aparentados quanto possibilita a transposição dessa regra para aplicá-la sobre objetos cujas analogias com os casos mais familiares não são óbvias.

Dito isso, antes de encerrarmos este item, cabe uma ressalva: a análise da vagueza ou da precisa imprecisão que unifica os usos de um conceito não advoga em favor de algum impressionismo pedagógico, tampouco borra as diferenças entre concepções pedagógicas concorrentes, nutrindo uma atitude indiferente em relação a elas. É evidente, por exemplo, que uma escola em que o criticismo não é um valor em si mesmo evitará expor seu aluno a problemas que põem em xeque regras infalíveis, habituando-o a esperar uma regra prêt-à-porter para todo tipo de situação. E, com efeito, esse é um ponto para o qual várias pedagogias renovadas, desde fins do século XIX, souberam chamar a atenção.

\section{A caixa-preta da cognição ou o fascínio das metáforas educacionais}

A adoção da pedagogia das competências como referência de avaliação pelo Exame Nacional do Ensino Médio (ENEM) representou um impulso decisivo para sua ampla difusão nas escolas brasileiras. Segundo José Mário Pires Azanha, haveria um essencialismo cognitivo

12- Estendemos um conceito do mesmo modo que, para tecer um fio, torcemos fibra com fibra: "E a robustez de um fio não está no fato de que uma fibra o percorre em toda sua longitude, mas sim em que muitas fibras estão trançadas umas com as outras" (WITTGENSTEIN, 1999, \# 67). 
subjacente nesse exame de competências e a sua consequência mais problemática seria a coisificação de processos mentais:

Em textos oficiais recentes, a palavra "competência" corre sério risco de ser coisificada como novo habitante do bestiário pedagógico que, querem nos fazer crer, são coisas que a educação deve desenvolver. Esse risco pode ter graves consequências pedagógicas, principalmente porque, em alguns textos, competências são contrapostas a conhecimentos, como se as escolas de formação geral [...] devessem se preocupar mais com a constituição daquelas do que com o ensino destes, como se fosse possivel alguém tornar-se um matemático competente pelo desenvolvimento de uma "coisa" que se chama "competência matemática" distinta do estudo intensivo de tópicos da matemática. (AZANHA, 2006, p. 167).

Contudo, quem pretenda encontrar em Perrenoud a fonte desses equívocos há de se surpreender ao descobrir que ele assinaria embaixo boa parte das críticas que Azanha (2001) endereça aos fundamentos pedagógicos do ENEM. Todavia, gostaríamos de mostrar que os formuladores da primeira versão do ENEM (vigente entre 1998 e 2008), alvo da crítica de Azanha, não fizeram uma leitura totalmente descabida de Perrenoud. Por isso, a análise de algumas ambiguidades presentes na maneira como Perrenoud representa o processo cognitivo e mobiliza os seus referenciais teóricos talvez seja um caminho mais promissor na abordagem dessa questão.

Perrenoud escora o conceito de competência sobre o conceito de habitus, de Pierre Bourdieu. A apropriação que Perrenoud (1999, p. 24-25) realiza desse conceito sugere-nos uma pista, se não um sintoma, para investigar o essencialismo flagrado por Azanha na pedagogia das competências. Habitus: do que se trata? Para Bourdieu (1983, p. 65) esse conceito se refere a um:
[...] sistema de disposições duráveis e transponíveis que, integrando experiências passadas, funciona a cada momento como uma matriz de percepções, apreciações e ações e torna possivel a execução de tarefas infınitamente diversas, graças às transferências analógicas de esquemas, que permitem resolver os problemas da mesma forma.

Estudar a gênese social da racionalidade prática de agentes cujas condutas possuem uma dinâmica irredutível à obediência intencional a regras ou à causalidade mecânica (seja ela social ou cerebral): eis o alvo do conceito de habitus (BOURDIEU, 1983). Perrenoud encontrou nesse conceito o caminho para elucidar a regularidade que possibilita os improvisos e as inovações dos indivíduos - valores caros à pedagogia das competências. Todavia, ele extrapola discretamente o escopo em que Bourdieu o emprega. 0 sociólogo francês deixa claro que pretende mostrar a dimensão criativa das nossas disposições adquiridas sem reduzi-las a entidades mentais ${ }^{13}$. Entretanto, Perrenoud levará sua teorização além desse limite.

A fundamentação das competências não encontrará no conceito de habitus uma explicação de ordem cognitiva que, por essa razão, é remetida ao campo das ciências cognitivas, ou melhor, ao seu desenvolvimento vindouro, pois, como Perrenoud reconhece em mais de uma ocasião ${ }^{14}$, não há consenso no campo das ciências cognitivas a respeito da pertinência da noção de competência. Por um lado, é preciso esperar as ciências cognitivas; por outro lado, o pedagogo das competências não pode esperar ${ }^{15}$. Esse impasse vem à tona

13- Bouveresse (1995, p. 591) enfatiza que a recusa de Bourdieu em subordinar a regularidade prática dos agentes a estruturas mentais formais se manifesta tanto na recusa do termo sujeito quanto na opção por substituí-lo pelo pleonasmo "agente que age".

14- Cf. a introdução e a conclusão de Construir as competências desde a escola (PERRENOUD, 1999).

15- É sintomático que, passados quinze anos, os defensores das competências continuem dizendo que é preciso esperar que as ciências cognitivas entrem em acordo e estabeleçam uma teoria cognitiva da mobilização dos recursos intelectuais. É o que lemos em texto recente de Michel Tozzi (2012, p. 32). 
quando Perrenoud trata da avaliação escolar das competências:

É verdade que se poderia descrever um conjunto de ações que remetesse para a competência subjacente, sem perguntar como ela funciona. Talvez assim fosse possivel nomear, classificar, elencar as competências ao acrescentar o verbo "saber" a um verbo que caracterize um conjunto de ações semelhantes. [...] Porém essa forma de tautologia não é suficiente quando se quer formar em competências. Precisa-se então de um inventário dos recursos mobilizados e de um modelo teórico da mobilização. É preciso formar uma ideia do que ocorre na caixa-preta das operações mentais, mesmo com o risco de que não passem de representações metafóricas no estágio das ciências da mente. (PERRENOUD, 1999, p. 20).

É o que Perrenoud fará no capítulo nomeado "Mobilizar os recursos: uma estranha alquimia”, em que descreve a tal caixa-preta das operações mentais em termos de tramas, esquemas, encaixes e até mesmo encaixes de bonecas russas, enfim, uma série de imagens e metáforas mecanicistas. Seria preciso então questionar: a que preço? Pois, embora a operação pareça resumir-se a uma questão estilística, vale a pena lembrar que "Toda uma nuvem de filosofia se condensa numa gota de gramática" (WITTGENSTEIN, 1999, pt. II, p. 214). Por isso, a análise filosófica deve investigar inclusive as mais discretas gotas do discurso pedagógico. Se Perrenoud desse a devida atenção a suas metáforas, explicitando o seu escopo e limites, poderíamos admiti-las ou recusá-las de modo mais judicioso, ponderando os caminhos pelos quais elas levariam nossos planos de investigação educacional.

0 primeiro caminho possivel a que somos conduzidos é a busca pelas competências básicas - quais são elas? Nossos saberes seriam organizados e mobilizados por competências, mas, por outro lado, uma competência pode ser mobilizada por outras competências. Assim, por mais que abríssemos as bonecas russas, sempre,encontraríamos uma ainda menor, sem nunca chegarmos à ultima, num esforço cujo risco seria a regressão ao infinito. Poderia ser dito, em defesa do pensador suíço, que pelo menos ele sabe que não passam de metáforas. Sim, mas, ao sugerir que o tempo permitirá às ciências cognitivas confirmá-las ou refiná-las, sugere que a gramática das competências virá a ser justificada pela descoberta de entidades mentais, isto é, que há uma referência objetiva para aquelas analogias ${ }^{16}$. A esse respeito, poder-se-ia dizer o que Wittgenstein, em um de seus cursos de Cambridge, afirma acerca da imagem mecânica na gramática do conceito de compreender:

[...] embora o conceito não se refira a uma maquinaria, sua gramática veicula a imagem de um mecanismo. Nós cremos que se víssemos apenas a maquinaria, nós entenderíamos o que é compreender (WITTGENSTEIN, 2001, p. 92, tradução minha).

A metáfora empregada em tal registro cria uma expectativa que obscurece o conceito em vez de esclarecê-lo: estamos prestes a coisificar conceitos referentes às operações mentais. Essa tentação insinua-se em escritos de Perrenoud, nos quais os problemas do aprendizado parecem ser traduziveis em termos de uma engrenagem cognitiva.

\section{Pedagogia das competências: a} força da ambiguidade ${ }^{17}$

A pedagogia das competências, ao transpor os conceitos das ciências cognitivas para o campo educacional, abstrai o jogo de linguagem no qual aqueles adquirem

16- Há uma reversibilidade entre metáforas e analogias. Toda metáfora é suportada por uma analogia básica. A este respeito, ver Perelman e Olbrechts-Tyteca (1996, p. 423-466).

17- Segundo os sociólogos Ropé e Tanguy (1997, cf. Introdução), a compreensão da hegemonia dessa pedagogia sobre o campo educacional deve destacar a ambiguidade e polissemia de seus conceitos como parte de sua eficácia. 
significado. Apesar de não haver uma definição consensual de competência no campo das pesquisas cognitivas, uma característica em comum merece destaque: trata-se de um modelo que direciona a investigação em laboratórios experimentais. Por isso, não se pode descurar que proposições hipotéticas sobre competências ali produzidas, quando transferidas para 0 campo pedagógico, mudam de estatuto, uma vez que ganham um emprego normativo. Psicólogos cognitivos têm feito alertas para as dificuldades envolvidas nessas transposições.

Segundo Spinillo e Roazzi (1989), pesquisadores do departamento de psicologia experimental da universidade de 0xford,

[...] o pedagogo na tentativa de operacionalização dos resultados da pesquisa psicológica, em uma perspectiva instrumental e até reducionista, tende a abstrair os dados do contexto teórico onde estes estão inseridos, advogando para si o supremo papel de organizador e elaborador destes a nível prático, incorrendo por sua vez no problema de dar um enfoque simplista a questões complexas, generalizando conclusões e padronizando procedimentos. (SPINILL0; ROAZZI, 1989, p. 24).

0 eventual avanço das pesquisas no campo da psicologia não implica imediatamente avanços pedagógicos: são campos de pesquisa institucionalizados com seus tempos e propósitos próprios. Transpor um modelo de um campo a outro é o mesmo que escolher uma jogada exitosa num determinado jogo e reproduzi-la em outro jogo com regras diferentes. Evidentemente, a transposição não está fadada ao fracasso de antemão, mas seu êxito dependerá das características específicas do novo campo.

A análise dos usos da linguagem promovidos por Perrenoud (1999a) deve ainda destacar que sua argumentação em Construir as competências desde a escola opera em dois níveis diferentes que, quando interagem entre si, podem ocasionar os deslizes que estamos apontando neste artigo. A entonação analítica e sóbria que caracteriza seu texto quando ele trata de questões epistemológicas ou curriculares é abandonada quando ele passa aos aspectos político-pedagógicos da reforma proposta. Nesses momentos, a argumentação ganha um acento interpelador dirigido ao professor, ao legislador, ao aluno.

Descobrimos que a reforma deve ser global e sistêmica, reorganizando (se não refundando) por inteiro a vida escolar: reconstruir as transposições didáticas, revisar a divisão disciplinar do tempo, promover ciclos, alterar os modelos avaliativos, reformular a formação docente (PERRENOUD, 1999, p. 74). Para escrever um programa orientado por competências, é preciso "coragem" (p. 50.), para que ele chegue a bom termo, é preciso que todos os atores envolvidos concedam total “adesão” (p. 84-85) para a realização dessa “utopia sociológica” (p. 84). Em suma, trata-se não apenas de uma proposta, mas de um apelo. Visando a conquistar a adesão, Perrenoud não está simplesmente explicando sua proposta, mas está tratando de nos persuadir à ação $0^{18}$.

Nesse registro, o que está em jogo é a adesão prática aos princípios da pedagogia das competências, antes do que uma eventual verificação científica do modelo proposto. As proposições sobre competências não são recebidas - não são usadas - no campo pedagógico como confiáveis porque fundamentadas (ou quase) nas ciências cognitivas. Elas atuam antes como normas, fundamentos em relação aos quais as questões do universo escolar devem prestar contas e eventualmente ganhar sentido. A adesão demandada por essa pedagogia visa, desse modo, a redesenhar nossa imagem de mundo escolar.

Que o autor interpele nossa vontade e tente nos persuadir não são problemas a priori. 0 que resulta problemático é o embaralhamento entre os registros normativo e descritivo. Ele

18 - Um bom resumo da distinção e polêmica entre persuasão e convencimento, tão antiga quanto o embate entre sofistas e filósofos na Grécia antiga, pode ser encontrado em Perelman e Olbrechts-Tyteca (1996, p. 29-34) 
sugere ao leitor que aquilo que depende de sua adesão precisaria se fundamentar por meio de verificação científıca, apresenta como um déficit dos saberes pedagógicos aquilo que, na verdade, diz respeito aos projetos de ação dos educadores. Isso, inclusive, produz um efeito colateral imprevisto na argumentação de Perrenoud, pois faz parecer que a adesão a sua proposta nesse contexto possui algo de irracional.

Evidentemente, não é essa a conclusão a que esse artigo pretende levar. Diante de uma sentença como a seguinte: "A principal dificuldade teórica [sic] na redação de um bloco [de competências] é a descoberta do encaixe tipo bonecas russas" (PERRENOUD, 1999, p. 50), não deveríamos concluir que se trata de um enunciado pré-científico, mas interpretá-lo inteiramente como metáfora educacional que pode eventualmente orientar a ação docente e cujos limites devem ser explicitados.

Tanguy e Ropé, já no início dos anos noventa, mostraram que o discurso das competências "modela a realidade ao mesmo tempo em que a justifica” (ROPÉ; TANGUY, 1997, p. 18). Diagnóstico preciso que, em outros termos, pode ser expresso assim: pretendem expor o que o ensino é, enquanto afirmam como ele deve ser. Tratar os modelos não como critérios, mas como pré-juízos, aos quais a realidade deva corresponder, é justamente a característica do uso dogmático dos modelos segundo Wittgenstein:

Só podemos evitar a injustiça ou o vazio de nossas afirmações na medida em que apresentamos o modelo como aquilo que ele é, ou seja, como objeto de comparação - por assim dizer, como critério -; e não como prejuízo, ao qual a realidade deva corresponder. (0 dogmatismo no qual tão facilmente caímos ao filosofar). (WITTGENSTEIN,1999, \# 131).

Por fim e em suma, Perrenoud não estaria certo em protestar contra descrições tautológicas das competências, encorajando a reflexão pedagógica a abrir a caixa preta das cognições por meio de uma investigação mais profunda? É possível responder negativamente de uma perspectiva wittgensteiniana. A inovação proposta por Perrenoud oferece-nos menos respostas que dificuldades. Podemos enxergar o inusitado uso que a expressão conhecimento adquire na pedagogia das competências não por um reflexo do atual estágio das ciências cognitivas, mas por sinal do uso reificado da linguagem, veiculado por um anseio de profundidade (adentrar a caixa-preta da cognição), que debelaríamos se considerássemos que:

Os problemas que nascem de uma má interpretação de nossas formas linguísticas têm o caráter de profundidade. São inquietações profundas; estão tão profundamente enraizadas em nós quanto nossas formas linguísticas, e sua importância é tão grande quanto a de nossa linguagem. (WITTGENSTEIN, 1999, \# 111).

A profundidade da investigação filosófica foi muitas vezes considerada como razão de seu brilho. Todavia, a partir de Wittgenstein, vemos como essa busca nunca satisfeita termina por colocar a própria filosofia em crise. Trabalhemos para que a pedagogia não padeça sob o mesmo impulso. Se é contra o risco do dogmatismo que a filosofia da educação deve lutar, combater a força de imagens que direcionam unilateralmente o pensamento será o seu propósito e abandonar esse anseio de profundidade talvez seja o seu preço. 


\section{Referências}

AZANHA, José Mário Pires. A formação do professor e outros escritos. São Paulo: Senac, 2006.

AZANHA, José Mário Pires. ENEM: afinal do que se trata? Jornal da USP, São Paulo, n. 20-26, ago. 2001.

BOURDIEU, Pierre. Esboço de uma teoria da prática. In: ORTIZ, Renato (Org.). Pierre Bourdieu: sociologia. São Paulo: Ática, 1983.

BOUVERESSE, Jacques. Régles, dispositions et habitus. Critique: Révue Générale de Publications Françaises et Étrangères en General, Paris, v. 48, 1995.

HADOT, Pierre. Wittgenstein et les limites du langage. Paris: Librairie Philosophique J. Vrin, 2005.

KUHN, Thomas. A estrutura as revoluções científicas. São Paulo: Perspectiva: 1998.

MORENO, Arley. Wittgenstein através das imagens. Campinas: Edunicamp, 1995.

MORENO, Arley. Introdução a uma pragmática filosófica: de uma concepção de filosofia como atividade terapêutica a uma filosofia da linguagem. Campinas: Edunicamp, 2005.

PASSMORE, John. La enseñanza del criticismo. In: PETERS, Richard (Org.). El concepto de educación. Buenos Aires: Paidós, 1969.

PERELMAN, Chan; OLBRECHTS-TYTECA, Lucie. Tratado da argumentação: a nova retórica. São Paulo: Martins Fontes, 1996.

PERRENOUD, Philippe. Construir as competências desde a escola. Porto Alegre: Artmed, 1999.

PERRENOUD, Philippe. Construire des compétences, tout um programme! Vie pédagogique, n.112, sept./oct. 1999a. (Dossier Faire acquérir des compétences à l'école). Disponivel em: <http://www.unige.ch/fapse/SSE/teachers/perrenoud/php_main/ php_1999/1999_14.html>. Acesso em: 14 set. 2014.

ROPÉ, Françoise; TANGUY, Lucie. Saberes e competências: 0 uso de tais noções na escola e na empresa. Campinas: Papirus, 1997.

SPINILLO, Alina Galvão; ROAZZI, Antônio. A atuação do psicólogo na área cognitiva: reflexões e questionamentos. Psicologia: Ciência e Profissão,. Brasília, v. 9, n. 3, 1989. Disponível em: <http://www.scielo.br/scielo.php?script=sci_arttext\&pid $=$ S1414-98931989000300008>. Acesso em: 14 set. 2014.

TOZZI, Michel. Une approche par competences in philosophie? Revue Rue Descartes, n. 74. Disponível em: <http://www.cairn. info/revue-rue-descartes-2012-1-page-22.htm>. Acesso em: 14 set. 2014.

WITTGENSTEIN, Ludwig. Fichas (Zettel). Lisboa: Edições 70, 1981.

WITTGENSTEIN, Ludwig. Da certeza. Lisboa: Edições 70, 1990.

WITTGENSTEIN, Ludwig. Wittgenstein's lecture. New York: Cambridge University Press, 2001.

WITTGENSTEIN, Ludwig. Investigações filosóficas. São Paulo: Nova Cultural, 1999.

Recebido em: 05.07.2013

Aprovado em: 15.04.2014

Rafael Ferreira de Souza Mendes Pereira é mestrando da Faculdade de Educação da Universidade de São Paulo. 